\title{
Evaluation of the Level of Anxiety among Iranian Multiple Sclerosis Fellowships During the Outbreak of COVID-19
}

\author{
Abdorreza Naser Moghadasi, MD $^{1^{*}}$ \\ ${ }^{1}$ Multiple Sclerosis Research Center, Neuroscience institute, Tehran University of Medical Sciences, Tehran, Iran
}

$\mathrm{T}$ The evidence and statistics published daily indicate that the prevalence rate of coronavirus disease 2019 (COVID-19) is increasing in Iran. ${ }^{1}$ Although no studies have been conducted in this regard, it seems that the level of anxiety among Iranian population is very high due to the outbreak of COVID-19. This anxiety may also affect the physicians and health care staff providing medical care to patients. Moreover, it must be taken into consideration that high level of anxiety can reduce individuals' attention, ${ }^{2}$ which is very hazardous for medical personnel. In addition, the incidence rate of multiple sclerosis (MS), which mostly affects the younger generation, is increasing among the Iranian society. ${ }^{3}$ As the mentioned disease mainly affects the younger generation, it has direct consequences for the community. Considering that the younger generation is the most important active force in any society, whatever making this generation ineffective can have a negative impact on the society as a whole. Therefore, it is imperative for physicians who are highly specialized in dealing with and treating MS to have a good mental health status and the least level of anxiety in the current situation. The present study was designed and conducted on March 6, 2020 to examine the anxiety level among Iranian MS fellowships. According to the latest statistics released by the MS Association of Iran, the number of MS patients in Iran is $78890,{ }^{4}$ for whom there are 18 MS fellowships offering care services. In this study, all 18 MS fellowships were asked to fill out the Beck Anxiety Inventory'; however, only 14 questionnaires were completed. Of these 14 fellowships, 7 were females and 7 were males. The mean age of the subjects was $40.58 \pm$
4.44 years. Moreover, the mean level of anxiety among the subjects was $5.24 \pm 3.79$, which can be categorized within the range of no anxiety according to the scale of this questionnaire. ${ }^{5}$ Of the 14 subjects, only two had mild level of anxiety, and no difference was observed between the sexes in terms of the level of anxiety. The findings of the study revealed that MS fellowships treating a significant portion of Iranian MS society are nearly not anxious in the current situation, which can also be an indicator of their mental well-being and a promise for MS patients to be provided with optimal services by their physicians.

\section{Conflict of Interest Disclosures}

None.

\section{Ethical Statement}

not applicable.

\section{References}

1. Coronavirus disease 2019 (COVID-19). Available from: https:// www.who.int/docs/default-source/coronaviruse/situationreports.

2. Najmi S, Kuckertz JM, Amir N. Attentional impairment in anxiety: inefficiency in expanding the scope of attention. Depress Anxiety. 2012;29(3):243-9. doi: 10.1002/da.20900.

3. Hosseinzadeh A, Baneshi MR, Sedighi B, Kermanchi J, Haghdoost AA. Incidence of multiple sclerosis in Iran: a nationwide, population-based study. Public Health. 2019;175:138-144. doi: 10.1016/j.puhe.2019.07.013.

4. Iranian MS society. Available from: https://cutt.ly/ttvGRDP.

5. Oh H, Park K, Yoon S, Kim Y, Lee SH, Choi YY, Choi KH. Clinical utility of beck anxiety inventory in clinical and nonclinical Korean samples. Front Psychiatry. 2018;9:666. doi: $\quad$ 10.3389/fpsyt.2018.00666. 